\title{
A summative assessment of theoretical and practical competencies in BLS-AED-An empirical research methodology to obtain quantitative results
}

Jordi Castillo García*1, Carmen Gomar Sancho², Encarnación Rodríguez Higueras ${ }^{1}$, Joan Maria Estrada Masllorens ${ }^{2}$, Alberto Gallart Fernández-Puebla ${ }^{1}$

${ }^{1}$ Universitat Internacional de Catalunya, Spain

${ }^{2}$ Universitat de Barcelona, Spain

Received: December 3, 2019

DOI: $10.5430 /$ jnep.v10n4p65
Accepted: December 16, 2019 Online Published: January 19, 2020

URL: https://doi.org/10.5430/jnep.v10n4p65

\begin{abstract}
Background and objective: The evaluation in basic life support (BLS) and automated external defibrillator (AED) training courses is mostly formative. The objective of the study was to evaluate a quantitative assessment with an established cut-off level of 7 out of 10 .

Methods: The course was designed in accordance with the European Resuscitation Council (ERC). For the evaluation a highfidelity manikin was available (Laerdal $($ R Resusci Anne QCPR). A multiple-choice questionnaire (MCQ) was used to test knowledge, and the practical skills with a high-fidelity manikin.

Results: About $68.2 \%$ and $34.1 \%$ obtained a score greater than 7 in knowledge and skills as evaluated by the nurse educator, immediately after the training. When the skills illustrated by the manikin were included, the results fell to $11.4 \%$ and $2.3 \%$, respectively.

Conclusions: A summative assessment of theoretical and practical competencies with a cut-off level of 7 demonstrates that global competency in BLS-AED is not achieved and some other strategies should be introduced in the current courses.
\end{abstract}

Key Words: Education, Cardiopulmonary resuscitation, Evaluation, Health care students

\section{INTRODUCTION}

The formula for survival in resuscitation describes three interactive factors - guideline quality (medical science), efficient education of caregivers of patients (education efficiency), and a functional chain of survival at the local level (local implementation) — as key determinants of survival after cardiac arrest. $^{[1]}$

In the education chapter of the 2010 guidelines of the European Resuscitation Council (ERC), it is recommended that all health care professionals must be able to demonstrate their competencies in basic life support (BLS) and automated external defibrillation (AED) and to be evaluated. The guidelines insist on an evaluation to ensure that the learning objectives are achieved and reliably retained to perform BLS with the necessary competence. ${ }^{[2]}$

The evaluation is carried out by nurse educators who are skilled at basic and advanced nursing practices and are able to teach and demonstrate them to their students. BLS courses are conducted by accredited instructors who need how to evaluate students in order to let them pass or repeat the course if

*Correspondence: Jordi Castillo García; Email: jordicastillogarcia@gmail.com; Address: Universitat Internacional de Catalunya, Spain. 
they fail.

Despite the introduction of assessment instruments ${ }^{[3-5]}$ was more than 20 years ago, there is no single instrument that can give information on all the components of professional competency in BLS-AED.

$\mathrm{CPR}$ and emergency cardiovascular care guidelines are regularly renewed and published by the American Heart Association (AHA) and European Resuscitation Council (ERC). Formal training programs are conducted based on these guidelines and, according to them, the assessment of overall competencies in the official and accredited BLS and AED courses are carried out by means of the dichotomous competent/incompetent classification. Given the difficult circumstances in which CPR must be performed, the evaluation should be more discriminative.

To target specific competencies better and obtain quantitative results, we deemed it necessary to introduce a cut-off score based on a combination of the content and skill assessment by the instructor, with the addition of including the assessment by a high-fidelity manikin, which would ensure that the student could perform high-quality BLS-AED.

The objective of the study was to evaluate the introduction of a quantitative assessment of the theoretical and practical competencies (by both the instructor and a high-fidelity manikin) immediately after a BLS-AED course and six months later, establishing a competency cut-off level of 7 out of 10 , with the aim of objectifying in a clear way students who achieve competency in BLS.

\section{MeTHODS}

This was a cross-sectional and descriptive analytical study of a single group, with tests after the end of the intervention and six months later. It was approved by the university's ethics committee.

An official BLS-AED course was held during the 2014-2015 academic year at an International University. The study population consisted of all first-year medical and nursing degree students who took the traditional, official, face-to-face course. The sample consisted of the students who signed the informed consent and who had not completed the accredited course in the previous three years. Paired data was obtained for the two study times.

The course was designed as a six-hour, face-to-face course and was accredited by the Local Committee of Cardiopulmonary Resuscitation in accordance with the European Resuscitation Council (ERC). In addition, the instructors were accredited under the ERC 2010 recommendations. ${ }^{[2]}$ The instructor/student ratio was $1 / 24$ in the theoretical lessons and $1 / 8$ in the skill practice sessions. The instructor continuously used feedback to correct skills.

The simulation materials met the ERC requirements; there

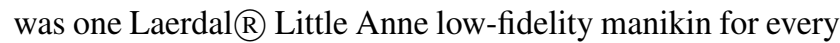
two students, a training AED for every eight students and a mouth-to-mouth guard for each student. For the practical evaluation, a high-fidelity manikin (Laerdal@) Resusci Anne QCPR) was available. ${ }^{[6]}$

The training was held on a single day and ended with an evaluation of knowledge and skills. The same evaluation was repeated after six months.

We used the overall Subjective Rating Definitions of Chamberlain et al. ${ }^{[7]}$ and we used a similar marking, considering a 7 a competent level, so the results are all referred to 7 (see Table 1). This overall rating was agreed to by a group of experts in competency evaluation in our university.

Table 1. Relationship between Overall Subjective Rating Definitions de Chamberlain and quantitative score at BLS AED

\begin{tabular}{|c|c|c|}
\hline Punctuation & Competences & Definition \\
\hline From 9 to 10 & Outstanding & $\begin{array}{l}\text { All skills were performed very well with no errors and almost exactly as described in the } \\
\text { standards. CPR performed in this way is likely. }\end{array}$ \\
\hline From 8 to 9 & Very good & $\begin{array}{l}\text { All skills were performed competently, although improvement is possible. Errors may be } \\
\text { minor; most were corrected. No serious errors in technique or sequence were made. CPR } \\
\text { performed in this way is likely to be effective and the victim would not be endangered. }\end{array}$ \\
\hline More than 7 & Competent & $\begin{array}{l}\text { Skills were crude and sometimes failed to meet standards; several steps may have been } \\
\text { out of sequence or were skipped, and/or some errors went uncorrected, although any } \\
\text { serious errors were corrected. CPR performed in this way would probably be effective } \\
\text { and the victim would not be endangered. }\end{array}$ \\
\hline From 5 to 7 & $\begin{array}{l}\text { Questionably } \\
\text { competent }\end{array}$ & $\begin{array}{l}\text { Skills were crude and often failed to meet the standard and/or serious errors were left } \\
\text { uncorrected. There may have been serious errors in sequence or delays. The chest was } \\
\text { compressed and some ventilations resulted in chest rise. CPR performed this way might } \\
\text { be effective. Errors might endanger the victim. }\end{array}$ \\
\hline Less than 5 & Not competent & $\begin{array}{l}\text { Skills were performed poorly or not at all; errors might seriously endanger a victim. CPR } \\
\text { may not have been performed. Efforts, if any, did not result in BOTH chest rise and } \\
\text { compression of chest. CPR performed in this way would probably not be effective and/or } \\
\text { the safety of the victim would be endangered }\end{array}$ \\
\hline
\end{tabular}

(Chamberlain et al., 2003) 
The three modes of measurement for competence were:

1) Knowledge. An official 11-question MCQ was carried out at the end of the training. Each question had the same value, and the global punctuation was recalculated up to 10 .

2) Practical skills measured by the instructor. A checklist was designed using the scale of Whitfield et al. ${ }^{[8]}$ with the modifications introduced by the 2010 recommendations. It had 35 key items and 12 essential dimensions for the evaluation of skills, which are safe approach, consciousness assessment, requests for help, airway permeabilisation, breathing, 999 calls, asking for AED, compression quality, mouth-to-mouth ventilation, defibrillator electrode placement, safe defibrillation and immediate compressions. ${ }^{[9]}$ Each dimension was given the same value, and the global punctuation was recalculated up to 10 .

3) Objective chest compression and mechanical ventilation data obtained automatically from the manikin software was used.6 The manikin offered 19 variables, giving an overall final value on a scale from 0 to 100 for the set of compressions and ventilations. We gave a value of 10 to the 100 points of the manikin scale.

We analyzed each part of the global competency in a separate way (knowledge, skill abilities and manikin results.

The qualitative variables were expressed as absolute frequency (n) and percentage (\%). The quantitative variables were expressed as the mean and standard deviation (SD). The temporal evolution for the two total quantitative data collection times was statistically analyzed with the paired
Student's $t$-test (with Bonferroni correction). The McNemar test was used for qualitative data.

The statistical analysis was carried out with SPSS software for Windows, version 15 (the version used at our university).

All the data collected in the theoretical and practical exams was transformed into a numerical scale from 0 to 10 to facilitate the statistical management and comparison of the results (as is common for academic scores). We considered students to have full competency in cardiopulmonary resuscitation (CPR) if they attained a score of 7 or greater in the three evaluation instruments: MCQ, instructor and high-fidelity manikin.

\section{Results}

A total of 44 students was part of the study sample at the end of the course (51.5\% were nursing students). The average age was $19.3( \pm 3.2)$ years, and $79.7 \%$ were women.

A score greater than 7 was attained by $86.3 \%$ of the students for theoretical knowledge; by $77.3 \%$ of students for the practical skills evaluated by the instructors; and by $13.6 \%$ (six students) when the skills (compressions and ventilations) were evaluated by the high-fidelity manikin. In the evaluation at six months after the course, a significant decrease was observed in the number of students with scores greater than 7 in theoretical knowledge $(68.2 \%)$ and practical skills evaluated by the instructors $(36.3 \%)$. In the skills evaluated by the manikins, three $(6.8 \%)$ students scored higher than 7 (see Table 2).

Table 2. Students with a score greater than or equal to 7 in knowledge and skills at the end of the course and 6 months later

\begin{tabular}{llll}
\hline & At the end of the course $(\mathbf{n}=\mathbf{4 4})$ & $\mathbf{6}$ months later $(\mathbf{n}=\mathbf{4 4})$ & $\boldsymbol{p}$ \\
\hline Knowledge & $38(86.3 \%)$ & $30(68.2 \%)$ & $\mathbf{. 0 4 1}$ \\
Skills assessed by instructor & $34(77.3 \%)$ & $16(36.3 \%)$ & $\mathbf{. 0 0 0 1}$ \\
Skills determined by manikin & $6(13.6 \%)$ & $3(6.8 \%)$ & .3 \\
\hline
\end{tabular}

Note. Values expressed as absolute frequency and \%. Values of $p<.05$ in bold.

If we consider together the knowledge and skills evaluated by the instructor, we can see that $68.1 \%$ of the students scored 7 when we considered the three together, and a total of $11.4 \%$ of the students attained a score greater than or equal to 7
(MCQ, instructor and high-fidelity manikin) after the course, which subsequently decreased to $2.3 \%$ at six months (see Table 3).

Table 3. BLS-AED competencies at the end of the course and at 6 months

\begin{tabular}{|c|c|c|c|}
\hline Assessments & $\begin{array}{l}\text { at the end of the course } \\
(n=44)\end{array}$ & $\begin{array}{l}6 \text { months later } \\
(n=44)\end{array}$ & $p$ \\
\hline knowledge & $38(86.3 \%)$ & $30(68.2 \%)$ & .041 \\
\hline knowledge + skills evaluated by instructor & $30(68.2 \%)$ & $15(34.1 \%)$ & .001 \\
\hline knowledge + skills evaluated by instructor + skills evaluated by manikin & $5(11.4 \%)$ & $1(2.3 \%)$ & .09 \\
\hline
\end{tabular}

Note. Values expressed as absolute frequency and \%. 


\section{Discussion}

Despite ongoing advances in resuscitation science, cardiac arrest survival rates remain suboptimal for both in-hospital and out-of-hospital settings. The literature on the acquisition and retention of resuscitation knowledge and skills clearly indicates that learner outcomes are suboptimal. ${ }^{[1]}$

Much effort is still needed to increase public awareness and improve the rates of bystander cardiopulmonary resuscitation (CPR) for victims of cardiac arrest. Education is the clue. ${ }^{[10]}$

The instruments used in current scientific publications are the evaluation of BLS-AED knowledge based on a multiplechoice questionnaire (MCQ) and the evaluation of skills on a simulated case by an instructor, using a performance checklist. ${ }^{[8,11]}$ More recently, the automatic monitoring of compression and ventilation manoeuvres, using a high-fidelity manikin, ${ }^{[12-14]}$ allows a more objective assessment of these manoeuvres; however, although essential, these manoeuvres do not evaluate all the components of competency.

Castillo et al. ${ }^{[15]}$ observed that checklist-based scores overestimate competence in CPR compared with recording strips of manikins in BLS courses. There is a discrepancy between check-list scores from the instructor and computerized recording scores from manikin. Instructors tend to double rate compressions as well as the ventilation.

Currently, the majority of course evaluations are carried out by means of the dichotomous competent/incompetent classification as a formative evaluation throughout the training by the instructor responsible for the class, which can have a markedly subjective component, with a tendency to be merely a spectator of errors and excessively optimistic when only the written test or the practical demonstration is evaluated. This means that the number of failing and non-accredited students is very small or non-existent. The international attitude is that the BLS-AED training, to be extendable to the whole population should not be punitive, but when the data are being analyzed quantitatively, as in this study, at least one third of the students trained should not be accredited after the training. This is a disappointing result if one takes into account the great CPR training effort that is done in our society and should encourage improvements in the teaching methodology.

In the knowledge assessment in our study at the end of the course, $86.3 \%$ of the students achieved scores greater than or equal to 7. The values are similar to those presented in the study by Reder et al. ${ }^{[16]}$ who obtained values greater than 7.5 for between $82 \%$ and $87 \%$ of the students in three methods of BLS training and AED use. Smith et al. ${ }^{[11]}$ approved students who achieved a score greater than 8 in an MCQ $(91 \%$ achieved this), and Madden ${ }^{[17]}$ reports that $72 \%$ of students surpassed 8.57 (which corresponded to 18 out of 21 correct questions). Currently, this type of knowledge evaluation is the most widely used in CPR training. ${ }^{[18,19]}$ Our number of questions was in the middle of the extremes we found in the literature. One study used eight questions, ${ }^{[20]}$ whereas others used $10^{[16]}$ or 21 questions. ${ }^{[17]}$ When dealing with CPR from the perspective of an eminently practical education, the great concern of all researchers was the acquisition of practical skills. We believe that practice is closely associated with knowledge.

In our study, the percentage of knowledge dropped significantly six months after training, with only $68.18 \%$ of the students achieving a score greater than or equal to 7 . The evolution of knowledge showed the same tendency as that found by Madden, ${ }^{[17]}$ when only $44 \%$ of the students attained an average score greater than 8.57. Madden started from a very high minimum score and a small sample size (18 participants); in addition, the students were retested at 10 weeks.

Up to this point, knowledge was easy to quantify, but the problem arose when the skill evaluation needed to be done.

Regarding the evaluation of skills, in 1997, Lester et al. ${ }^{[4]}$ validated a checklist called Cardiff Assessment of Response and Evaluation (CARE) that was modified in 1998 by Donnelly et al. ${ }^{[5]}$ and named Video and Recording Anne Printout (VIDRAP). In 2003, Whitfield et al8 made another modification, called "Cardiff test of basic life support and automated external defibrillation version 3.1". This instrument has been used by authors such as De Vries et al. ${ }^{[21]}$ in their research because this instrument fits all the necessary parameters for the evaluation of practical skills and is a reference in the literature. We also used it but have adapted it to the 2010 recommendations. ${ }^{[9]}$ Because there are no checklists similar to ours, we cannot compare our results with those of other articles.

The loss of skill over time is well-known. The results obtained show a similar trend in all studies, going from $77.27 \%$ of students with a score greater than 7 at the end of the course to $36.3 \%$ of students six months later. Einspruch et al. ${ }^{[22]}$ found that only $30 \%$ of the students would have performed an adequate demonstration at two months. With these results, we can reinforce arguments that are already known-that skills decline faster than knowledge ${ }^{[18]}$ but unfortunately, skill is what is needed for effective CPR.

At the end of the course, when we combined the results obtained by adding the scores of knowledge and skills evaluated by the instructor, we observed that $68.18 \%$ of the students 
obtained a score greater than or equal to 7.

CPR quality must be targetable. In CPR, some variables cannot be evaluated only by instructor observation due to their subjective nature, ${ }^{[15]}$ and they must be replaced with the introduction of new technologies and sophisticated manikins. The recommendations emphasize the importance of compressions and ventilation of a certain quality and with certain attributes and this is difficult to assess by the instructor through obser-

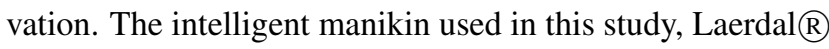
Resusci Anne QCPR, is the most widely used manikin for the objective assessment of these manoeuvres. ${ }^{[9,16,21]}$

The results obtained after evaluation with the manikin are worrisome, given that not even $13.6 \%$ of the students evaluated achieved 7 points; this value decreases the percentage of students who have a score greater than 7 in all three evaluations to $11.36 \%$ after training and $2.3 \%$ after six months. This data leads us to believe that the accredited CPR training fails to train students for the key manoeuvre of CPR, which is chest compressions with a $5 \mathrm{~cm}$ displacement of the sternum; therefore, these courses should use this type of manikin to give feedback and correct the students during training. In our study, this manikin was used only for evaluation and not for learning. As a result of our findings, we reinforce the conclusions of other authors who advocate training on manikins that give constant feedback to the student during the training. ${ }^{[23,24]}$

In view of our disappointing results, we think the educator community of CPR education should officially include some other strategies to improve the results.

To improve education, we can introduce some methods in our educational practice to ensure that the students are assuming their competencies or establishing a cut-off score in the middle of the course or at the end of it.

Deliberate practice is a highly structured activity, the explicit goal of which is to improve performance. First described by Ericsson et al., ${ }^{[25]}$ deliberate practice "includes activities that have been specially designed to improve the current level of performance", in which weaknesses are systematically identified and addressed to move to the next level. They highlight that repetition is not sufficient; rather, repetition should be paired with feedback directed at weaknesses and coupled with the assignment of specific exercises for the individual to address between sessions with the coach.

Resuscitation courses need to be structured to allow optimal feedback and debriefing practices. Mastery learning, a variety of competency-based education, means that learners acquire essential knowledge and skills, varying educational time among trainees. ${ }^{[26,27]}$

Published by Sciedu Press
Evaluation is a difficult task, and many methods have been tried to encourage nurses and educators to improve learning. Checklists and global rating scales (GRS) have long been debated. ${ }^{[28,29]}$

Many years ago, Angoff ${ }^{[30]}$ described a method to evaluate students. Since then, few studies have been conducted with this method, ${ }^{[31,32]}$ with both being critical of it. Since then, some other studies have been published, including a cut-off score. Saramma et al. ${ }^{[33]}$ and Rajeswaran et al. ${ }^{[34]}$ calculated the overall performance based on an average of a post-training knowledge score, and a score of $70 \%$ was set as a pass mark for overall performance. Others used steps in skills assessment that were graded and assigned penalty points, based on the participants' levels of performance. ${ }^{[34,35]}$

To evaluate the impact of a formal certified CPR training program on the knowledge and skill of CPR among nurses, we have used, in this study, a cut-off score according to the International Liaison Committee on Resuscitation (ILCOR) recommendations. ${ }^{[7]}$

In those guidelines, a more rigorous evaluation for a specific group (health workers, first responders and instructors) was demanded; the current recommendations focus on the teaching of high-quality CPR. These international recommendations give the instructors freedom to design the evaluation, whether formative or summative. In our study, evaluation instruments converted into 10-point scales were used to determine the students who reached a score of 7 in each instrument. Implementing a well-defined and more demanding evaluation helps ensure that students gain the competencies stated in the objectives of the course and allows for the investigation of other methods of learning. We must take into account that we are considering 7 out of 10, which means that students who achieve a 7 are highly competent.

The assessment was carried out independently for the three instruments used in the evaluation of the CPR training (theoretical exam, observation by the instructor and quality of compressions and ventilations registered by an intelligent manikin).

In our study, we use deliberate practice. Nurse educators gave advice and suggestions while the students practiced on the manikins but we did not introduce mastery learning. All students had the same time. Probably if we had introduced an extra time to those who did not reach the mastery standard, the results would have been much better, but this was not the objective of our study; rather it was to check whether our regular educational practice in our environment was reaching a standard by introducing only a quantitative value into the final evaluation. 
We believe that any future assessment instrument should combine assessment by instructor observation (who will assess other skills besides the compressions and ventilations) with the objective score given by the manikin. The 2015 guidelines ${ }^{[36]}$ already lean in that direction when they discuss high-quality CPR and discourage theoretical training classes.

In view of our results, we also recommend using high-fidelity manikins during the practice. The feedback the manikin gives should help learning, and the difference between nurse educator or instructor and manikin evaluation would not be so large. Nevertheless, cost-effectiveness might be considered. Resuscitation education should be configured to account for local resource availability.

The introduction of a cut-off-score in the courses with no programmed feedback and no addressed debriefing has demonstrated that mastery learning levels are not achieved and that

\section{REFERENCES}

[1] Cheng A, Brown LL, Duff JP, et al. Improving cardiopulmonary Resuscitation With a CPR feedback Device and Refresher Simulations (CPR CARES Study). A Randomized Clinical Trial. Jama Pediatr. 2015; 169(2): 137-144. PMid:25531167 https ://doi.org/10.1 001/jamapediatrics. 2014.2616

[2] Soar J, Monsieurs K, Balance J, et al. European Resuscitation Council guidelines for resuscitation, 2010. Section 9. Principles of education in resuscitation. Resuscitation. 2010; 81(10): 1434-1444. PMid:20956044 https ://doi.org/10.1016/j.resuscitatio n. 2010.08.014

[3] Brennan R, Braslow A, Batcheller AM, et al. A reliable and valid method for evaluating cardiopulmonary resuscitation training outcomes. Resuscitation. 1996; 85: 85-93. https://doi.org/10.1 016/0300-9572(96)00967-7

[4] Lester C, Morgan C, Donnelly P, et al. Assessing with CARE: an innovative method of testing the approach and casualty assessment components of basic life support, using video recording. Resuscitation. 1997; 34(1): 43-49. https ://doi .org/10.1016/S0300-9 572 (96) $01046-5$

[5] Donnelly P, Lester C, Morgan C, et al. Evaluating CPR performance in basic life support: the VIDRAP protocol. Resuscitation. 1998; 36(1): 51-57. https://doi.org/10.1016/S0300-9572(97)0 0092-0

[6] Laerdal. Session Viewer Software - Version 5.2.5821.26904. [Internet] 2013. Available from: http: //www . laerdal . com/es/Produ ctDownloads . aspx?product $I d=382$

[7] Chamberlain D, Hazinski M. Education in resuscitation: an ILCOR symposium. Circulation. 2003; 182(20): 2575-2594. PMid:14623795 https://doi.org/10.1161/01.CIR.0000099898.11954.3B

[8] Whitfield RH, Newcombe RG, Woollard M. Reliability of the Cardiff Test of basic life support and automated external defibrillation version 3.1. Resuscitation. 2003; 59(3): 291-314. https: //doi.org/10.1016/S0300-9572(03)00246-6 accredited BLS and AED courses carried out by means of the dichotomous competent/incompetent classification as a formative evaluation throughout the training is not enough to ensure competency. In view of the results, we strongly recommend introducing deliberate practice and mastery learning to improve the results and reduce the loss of knowledge and skills over time.

We conclude that the application of a summative evaluation with the objective of obtaining a score of 7 that combines knowledge, skills observed by the nurse educator and skills assessed by an intelligent manikin, shows that approximately one third of the students do not gain competency after a training course. Therefore, the evaluation should be more rigorous, and it is advisable to use high-fidelity manikins both in training and in the evaluation of practical skills.

\section{CONFLicts OF INTEREST Disclosure}

The authors declare no conflict of interest.
[9] Castillo-Garcia J, Gallart A, Rodríguez E, et al. Basic life support and external defibrillation competences after instruction and at 6 months comparing face-to-face and blended training. Randomised trial. Nurse Educ Today. 2018; 65: 232-238. PMid:29605787 https://doi.org/10.1016/j.nedt.2018.03.008

[10] Cheng A, Nadkarni VM, Mancini MB, et al. Resuscitation Education Science: Educational Strategies to Improve Outcomes From Cardiac Arrest. A Scientific Statement From the American Heart Association. Circulation. 2018; 138: e1-e48. https://doi.org/10.1161/CIR. 0000000000000583

[11] Smith KK, Gilcreast D, Pierce K. Evaluation of staff's retention of ACLS and BLS skills. Resuscitation. 2008; 78(1): 59-65. PMid:18406037 https://doi.org/10.1016/j.resuscitatio n. 2008.02.007

[12] Sánchez B, Algarte R, Piacentini E, et al. Low compliance with the 2 minutes of uninterrupted chest compressions recommended in the 2010 International Resuscitation Guidelines. J Crit Care. 2015; 30(49): 711-714. PMid:25797396 https : //doi .org/10.1016/j. jcrc. 2015.03.001

[13] King JM, Reising DL. Teaching Advanced Cardiac Life Support Protocols: The Effectiveness of Static Versus High-fidelity Simulation. Nurse Educ. 2011; 36(2): 62-65. PMid:21330894 https: //doi.org/10.1097/NNE.0b013e31820b5012

[14] Badir A, Zeybekoglu Z, Karacay P, et al. Using High-fidelity Simulation as a Learning Strategy in an Undergraduate Intensive Care Course. Nurse Educ. 2015; 40(2): E1-E6. PMid:25693075 https : //doi.org/10.1097/NNE.0000000000000134

[15] Castillo J, Gomar C, Rodríguez E, et al. Checklist-based scores overestimate competence in CPR compared with recording strips of manikins in BLS courses. Resuscitation. 2017; e14: e17. PMid:28286119 https://doi.org/10.1016/j.resuscitatio n. 2017.02.024

[16] Reder S, Cummings P, Quan L. Comparison of three instructional methods for teaching cardiopulmonary resuscitation and use of an automatic external defibrillator to high school students. Resuscitation. 
2006; 69(3): 443-453. PMid:16678958 https://doi.org/10.1 016/j.resuscitation .2005 .08 .020

[17] Madden C. Undergraduate nursing students' acquisition and retention of CPR knowledge and skills. Nurse Educ Today. 2006; 26(3): 218227. PMid: 16314002 https://doi.org/10.1016/j.nedt. 200 5.10 .003

[18] Hamilton R. Nurses' knowledge and skill retention following cardiopulmonary resuscitation training: a review of the literature. J Adv Nurs. 2005; 51(3): 288-297. PMid:16033596 https ://doi.org/ $10.1111 / j .1365-2648.2005 .03491 . x$

[19] López J, Martín H, Pereza J, Molina R, Herrero P. Novedades en métodos formativos en resucitación. Med Intensiva. 2011; 35(7): 433-441. PMid:21543134 https://doi.org/10.1016/j.medin . 2011.03 .008

[20] Pérez J, Becerro C, Beaskoexea L, et al. Reanimación Cardiopulmonar Básica en la formación de pre-grado de enfermería. Emergencias. 1998; 10(6): 376-380.

[21] De Vries W, Turner NM, Monsieurs KG, Biernes J, Koster R. Comparison of instructor-led automated external defibrillation training and three alternative DVD-based training methods. Resuscitation. 2010; 81(8): 1004-1009. PMid:20483519 https ://doi .org/10.1 016/j.resuscitation. 2010.04 .006

[22] Einspruch E, Lynch B, Aufderheide T, et al. Retention of CPR skills learned in a traditional AHA Heartsaver course versus 30-min video self-training: A controlled randomized study. Resuscitation. 2007; 74(3): 476-486. PMid:17442479 https://doi .org/10.1016/j . resuscitation.2007.01.030

[23] Mundell W, Kennedy C, Szostek J, et al. Simulation technology for resuscitation training: A systematic review and meta-analysis. Resuscitation. 2013; 84(9): 1174-1183. PMid:23624247 https: //doi.org/10.1016/j.resuscitation.2013.04.016

[24] Durante E. Algunos métodos de evaluación de las competencias: Escalando la pirámide de Miller. Educación Médica. 2006; 26(2): 55-61.

[25] Ericsson KA, Krampe RT, Tesch-Romer C. The Role of Deliberate Practice in the Acquisition of Expert Performance. Psychological Review. 1993; 100(3): 363-406. https://doi.org/10.1037/00 33-295X.100.3.363

[26] Wayne DB, Butter J, Siddall VJ, et al. Mastery learning of advanced cardiac life support skills by internal medicine residents using simulation technology and deliberate practice. J Gen Intern Med. 2006; 21: 251-256. PMid:16637824 https://doi.org/10.1111/j.15 $25-1497.2006 .00341 . x$
[27] Yudkowsky R, Park YS, Lineberry M, et al. Setting Mastery Learning Standards. Acad Med. 2015; 90: 1495-1500. PMid:26375263 https://doi.org/10.1097/ACM.0000000000000887

[28] Kim J, Neilipovitz D, Cardinal P, et al. A Comparison of Global Rating Scale and Checklist Scores in the Validation of an Evaluation Tool to Assess Performance in the Resuscitation of Critically Ill Patients During Simulated Emergencies (Abbreviated as "CRM Simulator Study IB”. Sim Healthcare. 2009; 4: 6-16. PMid:19212245 https://doi.org/10.1097/SIH.0b013e3181880472

[29] Ilgen JS, Ma IWY, Hatala R, et al. A systematic review of validity evidence for checklists versus global rating scales in simulating-based assessment. Medical Education. 2015; 49: 161-173. PMid:25626747 https://doi.org/10.1111/medu.12621

[30] Angoff WH. Scales, norms and equivalent scores. 2th ed. Washington, DC: American Council on Education. 1971.

[31] Van der Linden WJ. A latent trail method for determining intrajudge inconsistency in the Angoff and Nedelsky techniques of Standard setting. Journal of Educational Measurement. 1982; 19(4): 205-308. https://doi.org/10.1111/j.1745-3984.1982.tb00135.x

[32] Ricker KL. Setting Cut-Scores: A Critical Review of the Angoff and Modified Angoff Methods Ricker K. The Alberta Journal of Educational Research. 2006; 52(1): 53-64.

[33] Saramma PP, Suja PL, Dash PK, et al. Assessment of long-term impact of formal certified cardiopulmonary resuscitation training program among nurses. Indian J Crit Care Med. 2016; 20(4): 226-232. PMid:27303137 https ://doi .org/10.4103/0972-5229.1800 43

[34] Rajeswaran R, Cox M, Moeng S, et al. Assessment of nurses' cardiopulmonary resuscitation knowledge and skills within three district hospitals in Botswana. Afr J Prim Health Care Fam Med. 2018; 10(1): e1-e6. PMid:29781687 https://doi.org/10.4102/phcf m.v10i1.1633

[35] Ehlers VJ, Rajeswaran L. Cardiopulmonary resuscitation knowledge and skills of registered nurses in Botswana. Curationis. 2014; 37(1): e1-e7. PMid:26852428 https://doi.org/10.4102/cura tionis.v37i1.1259

[36] Monsieurs KG, Nolan JP, Bossaert LL, et al. ERC Guidelines 2015 Writing Group. European Resuscitation Council Guidelines for Resuscitation 2015: Section 1. Executive summary. Resuscitation. 2015; 95: 1-80. PMid:26477703 https://doi.org/10.1016/j.resu scitation.2015.07.039 